\title{
Emergency Response Organisation for Toxic Gas Emissions
}

\author{
Gérard Zufferey*
}

\begin{abstract}
Toxic gas emissions are the most severe chemical incidents, since chemicals disperse quickly from the source to the site and residential areas. Risk is minimised by design measures, alarm systems, and emergency response planning. Site personnel and people living in the vicinity must be informed and trained on the correct actions to take. The organization for possible incidents consists of a main command and control centre, a forward command centre and the fire brigade.
\end{abstract}

Keywords: Alarm system · Command and control centre - Emergency response planning · Toxic gas emissions · Training facilities

\section{Monthey Chemicals' Site}

The chemicals' complex at Monthey comprises three chemical manufacturing companies - Ciba Specialty Chemicals, Huntsman, and Syngenta Crop Protection together with a fourth company providing infrastructure and utility services, Cimo (Compagnie industrielle de Monthey). There are 80 different production buildings with a workforce of 2400 employees, while 27 tank farms with a total of over 600 vessels contain a wide range of chemical products.

\section{Toxic Gases}

The chemical products mentioned above include a number of toxic gases, such as chlorine, ammonia, phosgene, sulphur dioxide, and trimethylamine. Their characteristics differ greatly, as shown by the table of physical and chemical properties (Table). A similar table will provide some data of immediate use to the officer in charge of a HazMat unit, who can therefore

${ }^{*}$ Correspondence: G. Zufferey

Chef Protection d'entreprise

CIMO, Compagnie industrielle de Monthey SA

$\mathrm{CH}-1870$ Monthey

Tel.: +4124 4703652

Fax: + 41244703639

E-Mail: gerard.zufferey@cimo-sa.ch

www.cimo-sa.ch adapt his or her emergency response strategy appropriately. Definitions of several key parameters now follow:

Olfactory safety factor (OSF) is the ratio of the exposure limit as time-weighted average (TWA) to the olfactory threshold. The lower the value, the longer will it take the plant personnel to detect a leak.

Three ERPG (Emergency Response Planning Guide / American Industrial Hygiene Association) values have the following significance:

- ERPG-1 is the maximum airborne concentration below which it is believed that nearly all individuals could be exposed for up to $1 \mathrm{~h}$ without experiencing more than mild transient adverse health effects or perceiving a clearly defined, objectionable odour.

- ERPG-2 is the maximum airborne concentration below which it is believed that nearly all individuals could be exposed for up to $1 \mathrm{~h}$ without experiencing or developing irreversible or other serious health effects or symptoms which could impair an individual's ability to take protective action.

- ERPG-3 is the maximum airborne concentration below which it is believed that nearly all individuals could be exposed for up to $1 \mathrm{~h}$ without experiencing or developing life-threatening health effects.

In the case of the IDLH (Immediately Dangerous to Life and Health) parameter, it is worthy of note that the National Institute for Occupational Safety (USA) has published a revised table of IDLH values, which in certain cases are up to twenty times lower than their original values. The IDLH value is defined as an atmospheric concentration of any toxic, corrosive, or asphyxiant substance that poses an immediate threat to life or would cause irreversible or delayed adverse health effects or would interfere with an individual's ability to escape from a dangerous atmosphere within 30 min following the failure of his or her breathing apparatus.

\section{Accidental Release of Toxic Gas}

If a gas escapes, its physicochemical properties and physical state influence its diffusion, while its chemical structure determines its toxicity. In addition to the properties of the substance, other factors affect its dispersion rate, such as the quantity released, the meteorological conditions (wind speed and direction, atmospheric pressure, relative humidity, temperature, etc.) and the topography of the local environment.

The manifestations of chemical poisoning can be divided into two main groups: local disturbances and generalised disorders.

Disorders that are local or restricted to certain regions of the body develop in three stages:

- Irritations of the eye and respiratory tract, followed by a prickling sensation in the skin (face, hands). 
- Ocular burning and shooting pains, a sensation of heaviness in the chest, respiratory discomfort that may persist even after the toxic atmosphere has receded.

- Respiratory distress, cyanosis.

These problems are caused by halogenated chemicals (chlorine, bromine, iodine and fluorine compounds), certain nitrogen compounds (oxides of nitrogen, ammonia) and a number of sulphur compounds.

Generalised disorders involve:

- Symptoms of excitation or convulsions accompanied by aggressiveness, headaches or nausea. Symptoms of depression, drowsiness or even coma.

- Feelings of dizziness or muscular weakness.

- Digestive disorders.

- Rapid breathing, symptoms of depression, respiratory discomfort, respiratory arrest.

These generalised disorders are induced by anoxiants such as nitrogen, hydrogen and fluorine, by narcotic gases such as vapours from varnishes, solvents, ethers, certain hydrocarbons, or again, chlorinated products, as well as by cellular toxins such as carbon monoxide and hydrogen sulphide.

Finally, all these toxic gases can be found in the products of combustion resulting from a fire; an aspect often neglected in an emergency.

\section{How to Minimise the Risk of a Leak and/or Mitigate Its Effects}

\subsection{Design Measures}

The first question that must be asked is whether it is advisable to store the product. In certain cases, admittedly rare, it is possible to find another solution. At Monthey, for example, it has been decided to give up the storage of phosgene, replacing this by a system of synthesis on demand, with a supply system to the production buildings through a maximum-safety network (double containment, dry air purge through the jacket, on-line phosgene detection, analytical monitoring of the vented purge air and, in the event of an alarm, production stop and system purge).

If it proves necessary to store the product, it is advisable to implement all the safety measures dictated by the risk analysis. It could be necessary to install a gas detection system, which is possible for the principal toxic gases, or failing that, a leak detection system, depending on the case concerned.

At Monthey, we have implemented another precautionary measure by equipping all our tank farms with a water - or water and emulsifier - deluge system, which not only protects the tanks, but also creates a water curtain between the sections of the tank farm and at its perimeter.

\subsection{Organisational Measures}

\subsubsection{Alarm System}

To limit the consequences of an incident, it is vital that both the site personnel and the neighbouring population are given the alarm as quickly as possible. At Monthey, every building is equipped with alarms. If a toxic product escapes, we are in a position to set off the site gas alarm by one single action. In this case the site external sirens go off, the alarms within the buildings are activated and the illuminated panels (site gas alarm) light up. In every building on the site as well as in the local police station, devices connected to the telephone system simultaneously give a prerecorded alarm message. Information telephone No. 5 on the site also transmits a prerecorded message advising what action is to be taken. Local radio programs are automatically interrupted to allow a prerecorded message to be broadcast in several languages advising what action to take. Members of the fire brigade are automatically alerted by means of individual pagers. In short, all the actions mentioned above will have been implemented only a few seconds after the alarm is raised. It goes without saying that all employees know what action to take following this first alarm, and they are trained to do so. Regular exercises are carried out during the monthly alarm tests or as part of the safety days held in the site buildings. Turning now to the local population in the town of Monthey: they will be alerted quickly when the municipal alarm sirens are activated, as well as by the message broadcast on local radio. In addition, numerous training and information activities are provided in the community by the civic authorities

Table. Physical and chemical properties of some toxic gases

\begin{tabular}{|c|c|c|c|c|c|}
\hline Properties & Ammonia & Chlorine & $\begin{array}{l}\text { Sulphur } \\
\text { dioxide }\end{array}$ & $\begin{array}{l}\text { Trimethyl- } \\
\text { amine }\end{array}$ & Phosgene \\
\hline Boiling point & $-33^{\circ} \mathrm{C}$ & $-34^{\circ} \mathrm{C}$ & $-10^{\circ} \mathrm{C}$ & $3^{\circ} \mathrm{C}$ & $8^{\circ} \mathrm{C}$ \\
\hline $\begin{array}{l}\text { Relative vapour density } \\
(\text { air }=1)\end{array}$ & 0.6 & 2.5 & 2.3 & 2 & 3.4 \\
\hline $\begin{array}{l}\text { Solubility in water } \\
\left(\text { at } 20^{\circ} \mathrm{C}\right)\end{array}$ & $520 \mathrm{~g} / \mathrm{l}$ & $7 \mathrm{~g} / \mathrm{l}$ & $113 \mathrm{~g} / \mathrm{l}$ & $500 \mathrm{~g} / \mathrm{l}$ & - \\
\hline Explosive limits in air & $16-25$ vol \% & - & - & $2-11.6$ vol \% & - \\
\hline Olfactory threshold & 5 ppm & 0.05 ppm & $1 \mathrm{ppm}$ & 0.05 ppm & $0.5 \mathrm{ppm}$ \\
\hline $\begin{array}{l}\text { Exposure limit: } \\
\text { time-weighted average (TWA) }\end{array}$ & 20 ppm & $0.5 \mathrm{ppm}$ & $0.5 \mathrm{ppm}$ & - & $0.02 \mathrm{ppm}$ \\
\hline OSF (TWA/olfactory threshold) & 4 & 10 & 0.5 & - & 0.04 \\
\hline Short-term exposure limit (STEL) & 40 ppm & $0.5 \mathrm{ppm}$ & $0.5 \mathrm{ppm}$ & - & $0.04 \mathrm{ppm}$ \\
\hline IDLH & 300 ppm & 10 ppm & 100 ppm & - & 2 ppm \\
\hline ERPG-1 & 25 ppm & $1 \mathrm{ppm}$ & 0.3 ppm & 0.1 ppm & $\mathrm{n} / \mathrm{a}$ \\
\hline ERPG-2 & 150 ppm & 3 ppm & 3 ppm & 100 ppm & 0.2 ppm \\
\hline ERPG-3 & 750 ppm & 20 ppm & 15 ppm & 500 ppm & $1 \mathrm{ppm}$ \\
\hline
\end{tabular}


and the site management in order to make the population aware of what action to take in the event of an alarm.

\subsubsection{Emergency Response Planning}

Among the organisational measures we can cite the establishment of an emergency response plan for every building and every tank farm on the site. In addition to other information this includes the location of the building and the route to it for the fire brigade, the hydrants, the specific hazards and risks, a list of products and their exact locations, the feed and return lines for utilities and products, the means of combating the fire, the detection and extinguishing systems, the emergency exits and personnel assembly points, the locations of machinery, freight and personnel lifts, material safety data sheets and the containment facilities for fire runoff water.

\subsubsection{The Site Plan for Catastrophic Incidents}

In contrast to the above-mentioned emergency response plans, which relate to the particulars of individual buildings or tank farms, the site catastrophic incident plan has been drawn up for incidents whose consequences go beyond the boundaries of the site. It sets out to define the alarm schedule for all the organisations involved, the operational deployment plan and the tasks assigned to all the internal and external emergency services at the site. This plan has been worked out in close cooperation with the regional administrative authorities, the emergency services and the police forces of neighbouring municipalities and the Cantons of Valais and Vaud. Regular meetings of all the partners as well as exercises allow its efficacy to be tested. The last full-scale exercise, carried out in 2000, involved 250 emergency service personnel being called out.

\subsubsection{Organisation for Possible Incidents}

The organisation set up to deal with possible incidents at the Monthey site has the objectives of dealing effectively with all physical, biological, or chemical incidents, all emergencies relating to a product or a problem of safety or security, or all other critical situations that could impact negatively on persons or the environment, or on the well-being or good name of the companies.

This organisation must therefore take adequate measures to deal with an incident or reduce its negative effect to a minimum, and must ensure that there is good cooperation with the authorities and public services, and that the authorities, the site personnel, the media, the public and any other interested parties receive complete and accurate information.

This organisation comprises a main command and control centre, manned by a chief of staff, an officer responsible for communications, an officer responsible for protection of the site companies, and a chemicals adviser. This staff may be augmented by several specialists.

The function of the staff is:

- To assess the situation, to make the necessary decisions concerning the general safety of the site personnel, the firefighters, the site itself and the local population, to ensure that all internal and external organisations have been alerted, to call out the specialists whose presence is necessary, to ensure the coordination of emergency activities carried out by several bodies and specialists, to give support to the officer in charge of emergency services, to take charge of organising public relations, to liaise with the authorities, officials and the media.

- A forward command and control centre at the incident site, comprising a fire brigade officer in charge and an executive from the management of the affected zone. With the support of the fire fighting unit and possibly other supporting services, the officer in charge of the fire-fighters implements an emergency response strategy appropriate to the incident, following the fire-fighters' motto: 'Save, contain, extinguish, protect'.

\subsubsection{The Works Fire Brigade at the Monthey site}

The works fire brigade at the Monthey chemicals complex consists of a unit of professional fire-fighters together with a company of volunteer auxiliaries.

The 18 professional fire-fighters are commanded by a station officer and are divided into three teams. This ensures that there are always four men permanently present on the site and ready for any emergency response. They can be out of the fire station in less than $3 \mathrm{~min}$. This state of readiness is maintained around the clock, seven days a week and $24 \mathrm{~h}$ a day.

The auxiliary company is composed of 60 volunteer fire-fighters who normally work in the various companies on the site. These volunteers are divided into three groups with different skills: HazMat and radioactive protection specialists concerned with chemical incidents as well as fire fighting, appliance operators, and the measurement group. The latter group is equipped to identify the presence or absence of toxic gases in the atmosphere and to take samples of air, water, and soil.

The works fire brigade has five vehicles at its disposal, including an ambulance, plus specialised equipment suitable for chemical incidents.

The Cimo fire brigade also acts as an emergency response centre for chemical in- cidents and radioactive protection for the French-speaking part of the Canton of Valais.

In addition, we can also count on the support of a medical service with two doctors and five paramedics, as well as a group of twelve first aiders trained to provide emergency medical treatment.

\section{Emergency Response Strategy for Toxic Gas Escapes}

The officer in charge first of all decides the direction to take when approaching the incident site, selecting a route so as to have the wind coming from behind. He has the fire-fighters equipped with full fire fighting suits and self-contained breathing apparatus. If possible, he makes an initial analysis of the situation, which consists of investigating the type of gas and localising the leak, consulting the documentation, in particular the toxicological values, anticipating the movement of the gas cloud and evaluating the risks to the local population and the environment. He arranges for the vehicles to draw up at an appropriate distance from the emission: a minimum of $60 \mathrm{~m}$ away from minor leaks, at least $100 \mathrm{~m}$ away from major leaks.

After having made a swift reconnaissance, immediately communicating the results to the main command and control centre, he organises the emergency response: deployment of a minimum number of personnel in breathing apparatus and protective suits; deployment of personnel equipped to carry incident victims to safety, setting up of a water curtain, taking explosimetric and toxicity measurements systematically around the incident site, attempting to stop the leak, blocking off the drains and sewer system, redefining the incident zone on the basis of the measurement results (Fig. 1), installing a decontamination facility.

He then ensures that operations are conducted appropriately as the situation evolves.

\section{HazMat Unit Equipment}

Dealing with chemical incidents requires the use of special equipment, which in the case of items such as electrical cables, pumps, power tools, and radios must be explosion proof. Protective clothing and hoses must be resistant to chemical attack, with the use of stainless steel couplings. The HazMat specialists have earthing equipment to prevent the build-up of electrostatic charge, as well as the facilities and products necessary for decontamination. A system for recovering liquids, with several separate stainless steel tanks having a total 


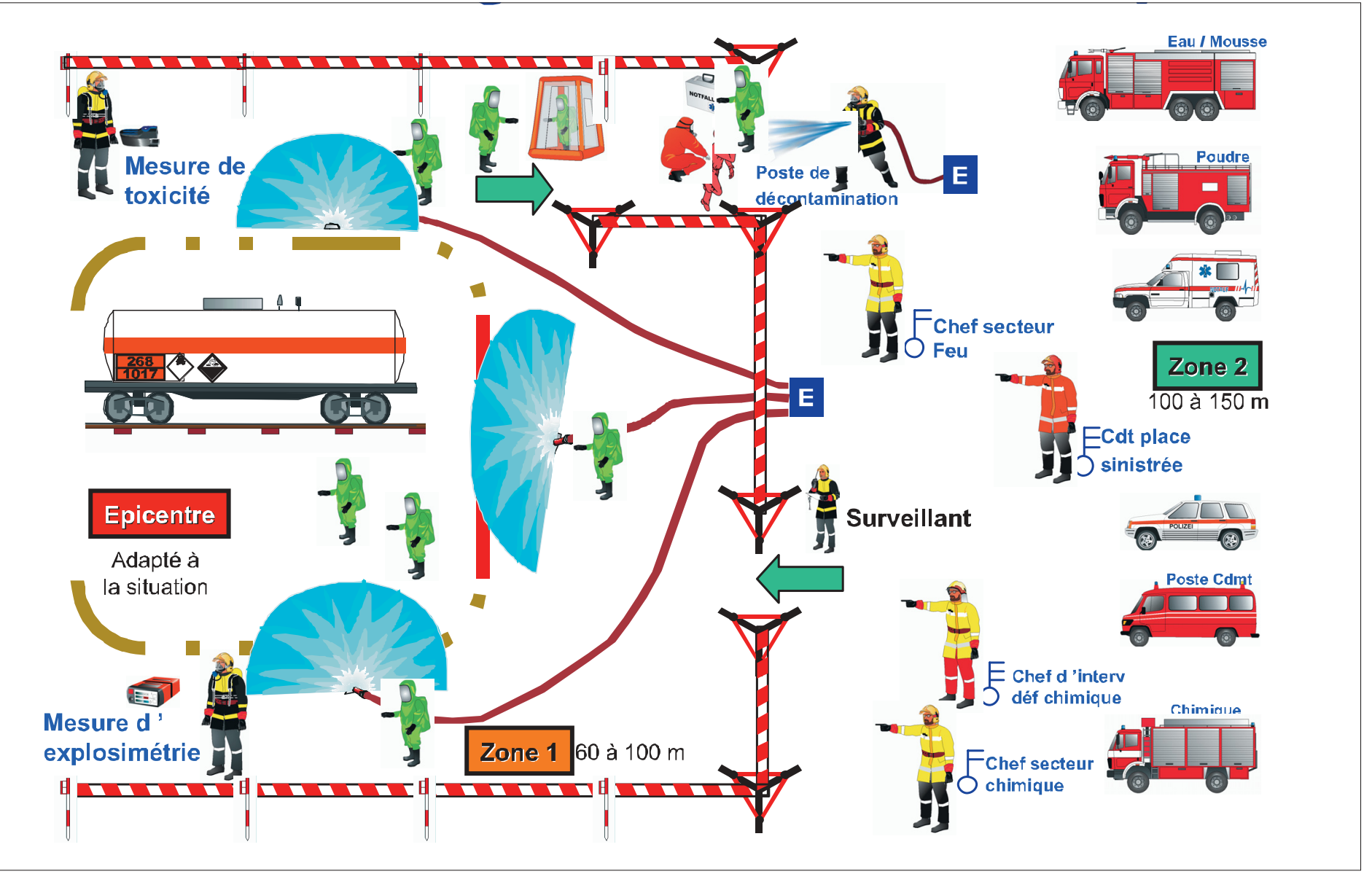

Fig. 1. Zone demarcation plan as basic strategy for emergency response to toxic gas emissions. The tasks fire protection and hazardous materials response are managed by two officers reporting to the officer in charge.

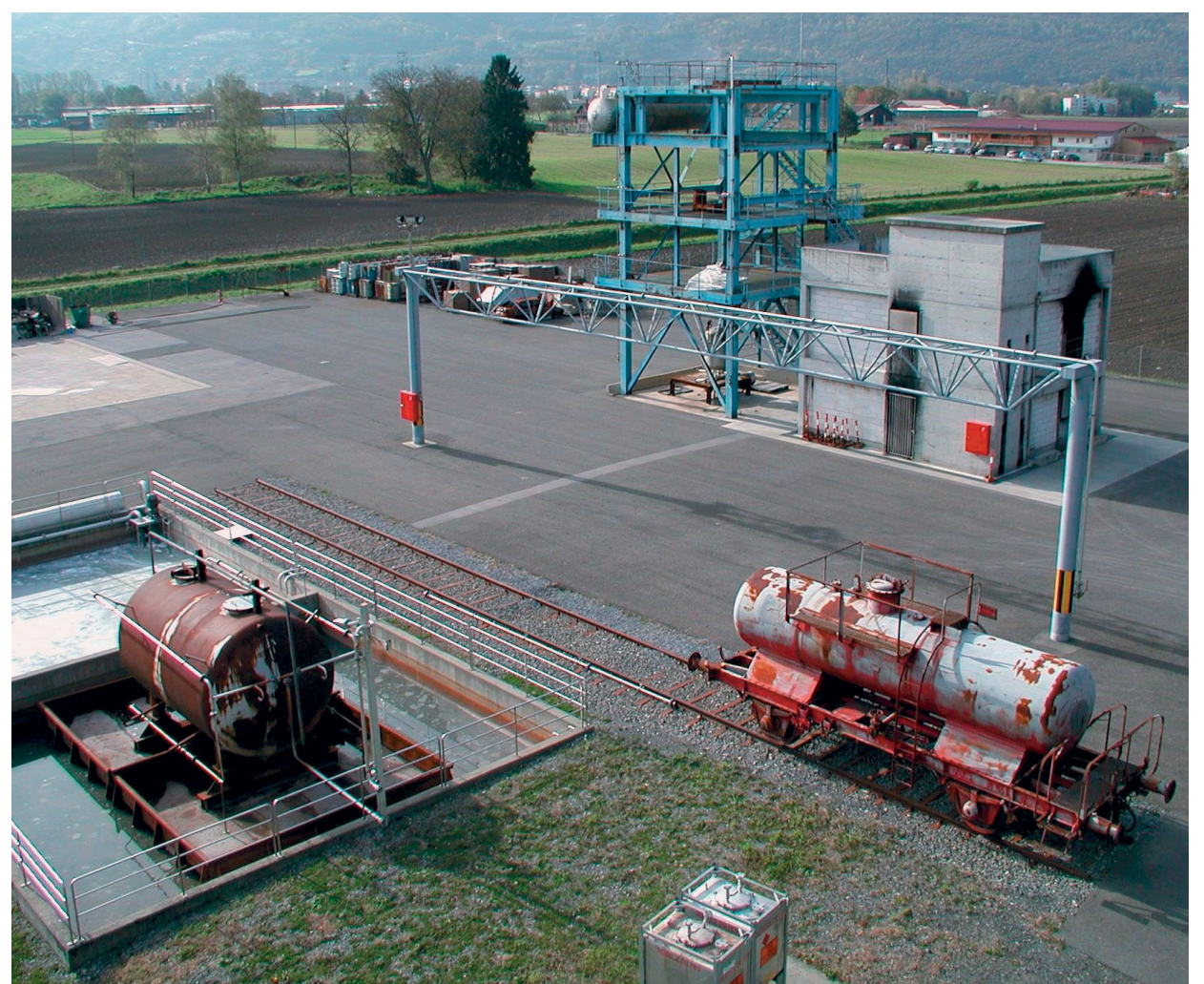

Fig. 2. Training facilities on the Monthey site with burn building, steelwork tower, open arena, tank, and railway wagon. capacity of 30001 , forms part of the basic equipment of the HazMat unit appliance.

\section{Training Facilities on the Monthey site}

The Cimo fire brigade has an exercise site (Fig. 2), on which part of the plant has been reproduced. There is a simulated house ('burn building'), a steelwork tower $13 \mathrm{~m}$ high, an open arena $\left(400 \mathrm{~m}^{2}\right)$ for large-scale fire fighting exercises, a pit with a reservoir, a rail track with a wagon (practice in stemming leaks), a tank (emergencies in a confined space) and an installation for demonstrating dust explosions.

The exercise site is used not only by the Cimo fire-fighters for training purposes, but also for safety days and fire safety schooling for site personnel. Local fire brigades in the region together with those from cities such as Lausanne and Neuchâtel also use the facilities (burn building) for training sessions in the chemical incident sector.

Received: December 5, 2003 